\title{
LA CONSTRUCCIÓN TEMÁTICA DE LA FILOSOFÍA DEL DERECHO DE LOS JURISTAS
}

\author{
J. Alberto DEL REAL ALCALÁ
}

\section{Resumen:}

En este texto trato de responder a la pregunta: ¿cuáles son los temas calificados generalmente como "de filosofia del derecho" que nos interesan a los juristas? Mi respuesta se dirige a desgranar cómo se ha ido construyendo el "contenido temático" más habitual que hoy identifica a la filosofia del derecho de los juristas (frente a la filosofia del derecho de los filósofos). Para tratar esta cuestión examino el punto de vista de Norberto Bobbio. En nuestro tiempo, dicha perspectiva constituye el punto de partida en la discusión de cuáles son los ámbitos problemáticos más habituales de la reflexión teórico-jurídica.

Palabras clave:

Temática de la filosofía del derecho de los juristas, teoría del derecho, teoría general del derecho, teoría de la justica, argumentación jurídica.

\section{Abstract:}

This essay answers the question: Which are the themes often considered as "Philosophy of Law" that are of concern to legal scholars? My answer seeks to sort out how the "thematic content" has become into what today is 


\section{J. ALBERTO DEL REAL ALCALÁ}

known as "Philosophy of Law" to legal scholars (against "Philosophy of Law" to philosophers). To deal with this question I will consider Norberto Bobbio's point of view.

\section{Keywords:}

Thematic Content of Jurist's Philosphy of Law, Legal Theory, General Jurisprudence, Theory of Justice, Legal Argumentation. 
SUMARIO: I. Introducción: la opción de la filosofía del derecho de los juristas como punto de partida contemporáneo. II. Convergencias y divergencias en la doctrina. III. Los juristas y la configuración actual de los temas de la filosofía del derecho. IV. Conclusión.

\section{INTRODUCCIÓN: LA OPCIÓN DE LA FILOSOFÍA DEL DERECHO} DE LOS JURISTAS COMO PUNTO DE PARTIDA CONTEMPORÁNEO

La cuestión controvertida sobre qué temas corresponden a la filosofia del derecho desde el punto de vista de los juristas y cuáles le son ajenos tiene como punto de partida la distinción de Norberto Bobbio acerca de las dos formas de hacer filosofia del derecho. Por una parte, concebir la filosofía del derecho como "filosofia del derecho de los filósofos", y por otra parte, entenderla como "filosofia del derecho de los juristas".

La primera opción (la filosofia del derecho de los filósofos) constituye un reduccionismo de lo jurídico porque supone enfocarla desde la filosofía, comprenderla desde la transposición de los grandes sistemas filosóficos en los que el derecho ocupa una porción muy pequeña, y donde meramente es sólo una pieza más (no el núcleo central) de la que dar cuenta dentro de un gran engranaje filosófico. Este camino para llegar a la filosofía del derecho tiene lugar "cuando en la construcción de su sistema [filosófico, el filósofo] se pregunta por el papel que en el mismo debe asignarse a la realidad jurídica", a fin de dar una explicación unitaria y sistemática de este elemento. ${ }^{1}$ Esta forma de hacer filosofia del derecho responde a opciones filosóficas generales que se aplican meramente al derecho, sin necesitarse siquiera para ello conocerlo. Y de hecho, la filosofía del derecho como mera "filosofia aplicada" de una filosofia general nos la encontramos a menudo elaborada "por filósofos que no

1 Pérez Luño, A.E., "El concepto de filosofía del derecho", Lecciones de filosofía del derecho. Presupuestos para una filosofía de la experiencia juridica, Mergablum, Sevilla, 1998, p. 75. 
conocen en absoluto el derecho, o tienen un conocimiento del mismo muy vago y superficial". ${ }^{2}$ El resultado es que "el filósofo del derecho no brilla con luz propia sino con luz refleja". ${ }^{3}$ Y es muy probable que esta filosofia del derecho de los filósofos, desconectada de la experiencia jurídica y de los problemas jurídicos, vaya a interesar muy poco a la comunidad de juristas. Tengo que aclarar que no es a esta clase de filosofia del derecho la que voy a tener en cuenta a la hora de considerar su construcción temática, en virtud de su condición de "ajena" a los juristas.

La segunda opción o forma de hacer filosofía del derecho no es como filósofos sino como "juristas": la filosofia del derecho de los juristas. Este modo de abordar la especulación teórico-jurídica o filosófico-jurídica no es ya desde la filosofía sino desde la "experiencia jurídica" misma. ${ }^{4}$ Se trata de una filosofia del derecho que responde a menudo a concepciones que son autónomas de los juristas, esto es, independientes de otras reflexiones filosóficas más generales, lo que no es óbice para que puedan establecerse otro tipo de conexiones sociales e intelectuales. Aquí, a diferencia del filósofo que se mete a jurista, "el jurista-filósofo [o teórico - teórico del derecho-] se plantea "filosóficamente" el problema del derecho cuando advierte la insuficiencia de los criterios técnico-jurídicos para desentrañar el sentido de sus conceptos fundamentales". ${ }^{5}$ Es decir, opera inversamente - partiendo de la experiencia jurídica- a como lo haría el filósofo que juega a ser jurista.

La mayor reivindicación de la filosofía del derecho de los juristas es que debe partir y desarrollarse desde una base

2 Guastini, R., "Imágenes de la teoría del derecho", Distinguiendo. Estudios de teoria y metateoria del derecho, Barcelona, Gedisa, 1999, p. 17.

3 Bobbio, N., "Naturaleza y función de la filosofía del derecho", Contribución a la teoría del derecho, edición a cargo de A. Ruiz Miguel, Madrid, Debate, 1990, p. 93.

4 Pérez Luño, A.E., "Concepto del derecho y experiencia jurídica", Lecciones de filosofía del derecho. Presupuestos para una filosofía de la experiencia juridica, cit., pp. 69-72.

5 Pérez Luño, A. E., "El concepto de filosofia del derecho", cit., p. 74. 
empírica: la realidad del derecho, la experiencia jurídica y el material aportado por la ciencia jurídica, y no otras vías etéreas. Téngase en cuenta que "una filosofia del derecho que pretenda ignorar a la ciencia jurídica es un error que conduce a una elucubración abstracta carente de base real". ${ }^{6}$ Por eso, la función que aquí adquiere la filosofía del derecho (de los juristas) es muy diferente a la anterior (la de los filósofos), cuyo campo de análisis ahora son aquellos problemas o aquellas cuestiones "jurídicas" que "no son abordadas de modo expreso o que los juristas dan por supuestas en su trabajo cotidiano de intérpretes del derecho positivo". ${ }^{7}$

Como jurista (que practica la filosofia del derecho), esto es, como teórico del derecho, esta clase de filosofía del derecho es la que me es familiar. Y es la que consideraré en este texto para abordar su delimitación temática, tratando de responder a la pregunta: ¿cuáles son los temas identificados generalmente como "de filosofia del derecho" que nos interesan a los juristas? Aquí, el referente principal es Norberto Bobbio. Para él, la filosofía jurídica "se compone de tres partes que llamo respectivamente: a) teoría del derecho; b) teoría de la justicia; c) teoría de la ciencia juridica". ${ }^{8}$ Estos tres campos temáticos dibujan en mayor medida el contorno de las "ramas" o sub-áreas de especulación a identificar como filosofía del derecho de los juristas. Entre ellas no figura - como puede constatarse - una explícita historia de la filosofía del derecho. La razón de tal ausencia no se encuentra en el rechazo del maestro italiano al criterio histórico como razón epistemológica, sino que responde a que el profesor de Turín no es partidario de "las historias de la filosofia del derecho como obras con sustantividad propia, porque generalmente son (y no pueden ser de otra manera) elencos de doctrinas más bien heterogéneas". Por lo que él

6 Peces-Barba, G., Introducción a la filosofía del derecho, Madrid, Debate, 1994, p. 161.

7 Ibidem, p. 94.

8 Ibidem, p. 98. La cursiva es nuestra. 
prefería "dirigirse a las doctrinas del pasado tema por tema, problema por problema" y no en un sentido sistemático, dada aquella heterogeneidad invencible. ${ }^{9}$

\section{CONVERGENCIAS Y DIVERGENCIAS EN LA DOCTRINA}

Desde un sentido clarificador de la cuestión que estamos examinando, parece aceptable asumir inicialmente la triada temática del profesor de Turín como punto de partida configurador de la filosofia del derecho de los juristas si esto nos ayuda a delimitar cuál es el contenido material de ese conocimiento iusfilosófico o teórico-jurídico, por lo habitual excesivamente borroso, difuso y confuso. Así, pues, además de que posibilita aclarar y particularizar cuáles son los temas principales sobre los que versa la filosofia del derecho desde el punto de vista del interés de los juristas, hay que decir que se trata de una división temática que goza de aceptación en la doctrina y se encuentra ciertamente extendida, constituyendo un núcleo aproximado de consenso a la hora de definir qué tipo de saber jurídico es el que aporta la filosofia del derecho en el conjunto del conocimiento del derecho, y cuál no le corresponde porque pertenece a otro campo cognoscitivo del derecho o de la filosofia. Sin embargo, dicho consenso temático no se ha salvado del debate doctrinal ni de críticas sólidas que lo han puesto en cuestión. Por lo que necesariamente le prestaremos atención. Eso sí, hay que reconocer que desde el señalamiento temático de Bobbio, las propuestas que lo discuten se limitan más bien sólo a revisarlo parcialmente en alguno de sus aspectos, pero sin ofrecer por lo general una alternativa integral.

En la doctrina, destacados filósofos del derecho - ya sean del ámbito iusnaturalista o positivista normativo o analitico- siguen aproximadamente la tripartición del italiano. El primero que hay que traer a colación es H. L. A. Hart, el

9 Ibidem, p. 99. 
cual ha divido la filosofia del derecho en "tres grupos de cuestiones" que concreta en los "problemas de definición y análisis, problemas de razonamiento jurídico y problemas de crítica jurídica”. ${ }^{10}$ Los problemas hartianos de definición y análisis coincidirian aproximadamente con la propuesta bobbiana de teoría del derecho. Los problemas hartianos de razonamiento jurídico, con la de teoría de la ciencia jurídica. Y los problemas hartianos de critica juridica son asimilables a la teoría de la justicia bobbiana. En la opinión del catedrático de la Universidad Carlos III de Madrid, Gregorio Peces-Barba, "se suele coincidir en estos tres temas, uno que reflexiona sobre el propio conocimiento científico sobre el derecho, sobre metodología y lógica jurídica, otro sobre el concepto de derecho y, por fin, otro, sobre los valores jurídicos, o la teoría del derecho justo". ${ }^{11} \mathrm{El}$ catedrático de la Universidad Autónoma de Madrid, Elías Díaz coincide en que "estas tres zonas de cuestiones son las que parecen proponerse, con mayor grado de convergencia entre los autores, como contenido de una filosofia jurídica actual". ${ }^{12}$

Desde la perspectiva del profesor de la Universidad de Salamanca, José Delgado Pinto, se observan del mismo modo los siguientes temas en la filosofia del derecho: "el tema de la justicia y del derecho justo", además "la elaboración de una teoría acerca de la realidad misma del derecho", que coincidiría con la propuesta bobbiana de teoría del derecho, y por último "la reflexión crítica sobre las cuestiones atinentes a una epistemología y a una lógica y metodología jurídicas", que se correspondería con la teoría de la ciencia jurídica bobbiana. ${ }^{13}$ De una opinión similar es Antonio Enrique Pérez Luño. El catedrático de la Universidad de Sevilla identifica a la temática iusfilosófica con el "ser", el "deber" y el "conocer" como temas generales de la filosofia

10 Hart, H. L. A., "Problems of the Philosophy of Law", Essays in Jurisprudence and Philosophy, Oxford, Clarendon Press, 2001, p. 89.

11 Peces-Barba, G., Introducción a la filosofía del derecho, cit., p. 251.

12 Díaz, E., Sociología y filosofía del derecho, Madrid, Taurus, 1993, p. 253.

13 Delgado Pinto, J., "Los problemas de la filosofia del derecho en la actualidad", Anales de la Cátedra Francisco Suárez, Granada, núm. 15, 1975, p. 38. 
pero referidos al campo del derecho. ${ }^{14} \mathrm{El}$ "ser" en el derecho se correspondería con la teoría del derecho. El "deber" en el derecho sería asimilable a la propuesta de teoría de la justicia; y el "conocimiento" en el derecho tendría su par en la teoría de la ciencia juridica de N. Bobbio. En la misma dirección se expresa Manuel Atienza. Para el catedrático de la Universidad de Alicante "Aunque propiamente no se pueda hablar de partes en la filosofia del derecho, es usual distinguir tres sectores que se corresponden con las tres cuestiones esenciales", que él concreta a las temáticas: "qué es el derecho", equiparable a la propuesta bobbiana de teoría del derecho; "cómo se puede conocer" el derecho, cuya correspondencia sería la propuesta de teoría de la ciencia jurídica; y finalmente al asunto de "cómo debería ser" el derecho, análogo a la propuesta de N. Bobbio acerca de la teoría de la justicia. ${ }^{15}$

Sin embargo, también existen en la doctrina opiniones divergentes que no son necesariamente tan coincidentes con la del profesor de Turín, y que merece la pena tener en cuenta. Me referiré a tres de ellas: las de Riccardo Guastini, Robert Alexy y Alf Ross. La perspectiva de Riccardo Guastini asume como punto de partida la triada temática de $\mathrm{N}$. Bobbio, pero a continuación se aleja a veces de ella. Según el profesor de la Università di Genova, "hay dos tipos de FD [Filosofía del derecho]: la FD de los filósofos (el método o estilo "filosófico" en FD) y la FD de los juristas. [Y] La FD de los filósofos es, según mi propuesta, la FD sin ulteriores especificaciones; la FD de los juristas no es otra cosa que la TD [teoría del derecho]". ${ }^{16} \mathrm{El}$ italiano aduce dos sentidos y dos razones para justificar a la teoría del derecho como Filosofia del derecho de los juristas. La primera razón es que ese tipo de Filosofia del derecho no puede ser practicada "más que por juristas profesionales (no se puede hacer este

14 Pérez Luño, A. E., Lecciones de filosofía del derecho. Presupuestos para una filosofía de la experiencia jurídica, cit., pp. 28-32.

15 Atienza, M., El sentido del derecho, Barcelona, Ariel, 2001, p. 249.

16 Guastini, R., "Imágenes de la teoría del Derecho", cit., p. 17. 
tipo de FD sin conocer el derecho)". Y la segunda razón es que la reflexión iusfilosófica ejercida por los juristas "es un ejercicio filosófico útil para los propios juristas (y quizá sólo para ellos): su objetivo fundamental es la crítica (y quizás el progreso) de la ciencia jurídica". ${ }^{17}$

Desde la perspectiva de Robert Alexy, determinar el contenido material de la reflexión iusfilosófica viene a equipararse con responder a la cuestión de cómo definir la naturaleza de la filosofia del derecho, para lo cual es necesario resolver las siguientes tres clases de problemas temáticos. El primer problema temático trata de la pregunta "en qué clase de entidades consiste el derecho, y cómo están conectadas estas entidades de tal modo que conforman la entidad global que llamamos "derecho"". Y se traduce en el problema del "concepto de norma y de sistema normativo", mientras que el segundo y tercer problema tienen que ver con "la validez del derecho". Concretamente, el segundo problema temático se pregunta "por la dimensión real o fáctica" del derecho y se circunscribe al área del positivismo jurídico. El tercer problema de la naturaleza de la filosofía del derecho está relacionado con "la corrección o legitimidad del derecho", y en este problema el asunto principal es "la relación entre derecho y moral". ${ }^{18}$ Para R. Alexy, esta "triada de problemas" constituye el meollo temático de la filosofía del derecho.

Y por último, la opinión de Alf Ross, que rotundamente diverge de la triada bobbiana a la hora de definir el contenido de la filosofia del derecho. Lo que diferencia en mayor medida su posicionamiento de los demás enfoques es que él declara la imposibilidad de predicar el carácter "sistemático" de la filosofia del derecho como saber jurídico sobre el derecho, ya que estima que la filosofia del derecho no tiene un "objeto propio" que pueda diferenciarla del que contempla la ciencia. Por lo que, desde su punto de vista, "no es

17 Ibidem, p. 18.

18 Alexy, R., "La naturaleza de la filosofia del derecho", Doxa, Alicante, núm. 26, 2003, p. 151. 
conveniente hablar [siquiera] de "filosofia del derecho" si con ello aludimos a un ámbito de investigación y cognoscitivo que se encuentra sistemáticamente delimitado, sino como mucho de "problemas iusfilosóficos" en el sentido de problemas jurídicos que en cada momento los observadores del derecho y los estudios jurídicos consideren que hay que enfocar desde el análisis filosófico. ${ }^{19}$

Tampoco coincide con la triada temática bobbiana el catedrático de la Universidad de León Juan Antonio García Amado. Desde su óptica, la filosofia del derecho abarca los siguientes ámbitos temáticos: ontología jurídica, epistemología jurídica, teoría general del derecho y filosofía socio-jurídi$c a$, denominación última en la que asimismo coincidiría con el catedrático de la Universidad de Murcia Rafael Hernández Marín. ${ }^{20}$

\section{LOS JURISTAS Y LA CONFIGURACIÓN ACTUAL \\ DE LOS TEMAS DE LA FILOSOFÍA DEL DERECHO}

En virtud de su utilidad delimitadora, probablemente es una opción correcta asumir que a la hora de dibujar el perfil del contorno problemático, temático, cognoscitivo e investigador contemporáneo de la filosofía del derecho de los juristas no debemos prescindir de los tres criterios bobbianos mencionados en el epígrafe anterior. Ellos nos pueden ayudar a identificar en mayor medida que otros indicadores el contenido de la tarea de los juristas que también ejercemos como filósofos del derecho y que nos negamos a aceptar el arrinconamiento del derecho y de la experiencia jurídica que caracteriza a la filosofía del derecho de los filósofos.

19 Ross, A., Sobre el derecho y la justicia, trad. de G. R. Carrió, Buenos Aires, Eudeba, 2006, p. 50.

20 García Amado, J.A., "La filosofía del derecho y sus temas. Sobre la no necesidad de la Teoría del derecho como sucedáneo", Persona y derecho, núm. 31, 1994, pp. 109-155. 
Un primer ámbito temático de la filosofia del derecho de los juristas ha sido construido como ontología jurídica" o teoría del derecho en sentido estricto, cuyo objeto cognoscitivo se ha centrado en el "ser" del derecho y versa principalmente sobre la determinación del concepto de derecho. ${ }^{21}$ Lo primero que hay que decir sobre el contenido de la teoría del derecho es que como parte integrante de la reflexión filosófico-jurídica, ella participa de las características de ésta ("problematicidad" y "criticidad"). Se trata de una especulación y de un saber centrado en los "problemas" sobre el ser del derecho. Téngase en cuenta que la "problematicidad" como rasgo identificador de la filosofía del derecho de los juristas la iguala con las demás disciplinas jurídicas al situar como punto de partida a los "problemas" de la "experiencia jurídica", desde la idea general de que la tarea principal del jurista es la de resolver los problemas (individuales y colectivos) de las personas. Y por otro lado, este espacio temático también está impregnado de una dimensión "crítica" sobre el ser del derecho, sobre las concepciones del derecho vigentes, esto es, su cuestionamiento, siendo su función precisamente la de determinar si esas concepciones son correctas o no lo son. Aquí, la "criticidad" como rasgo identificador de la filosofia del derecho "de los juristas", la distingue del resto de disciplinas jurídicas generando un "modelo de jurista crítico", y lo hace en contraposición a las demás materias que intervienen en la formación de los juristas, las cuales habitualmente suministran (explicita o implicitamente) un modelo de jurista "acrítico" - tal como lleva a cabo por lo general la dogmática jurídica-, mero conocedor del derecho positivo pero sin capacidad de evaluación del mismo. Claro está, en este ámbito cognoscitivo, dada la pluralidad de perspectivas desde las que se puede afrontar el concepto de derecho, la definición de un concepto unánime del derecho es tarea casi imposible, teniendo que acudir sin más remedio necesariamente a la aceptación de la diversidad de planteamientos. Esto puede ser un inconve-

21 Bobbio, N., "Naturaleza y función de la filosofía del derecho", cit., p. 98. 
niente porque bloquea una noción clara y ultra-perfilada del derecho, pero también una ventaja porque dicha diversidad es la expresión de la dimensión "crítica" que singulariza a la materia filosofia del derecho en cualquiera de sus ámbitos cognoscitivos en los que se expresa.

Claro están, como reflexión de carácter general sobre el ser del derecho, la teoría del derecho se eleva por encima de los elementos normativos particulares que proporciona la experiencia jurídica. A este respecto, puede ser una instancia óptima a la hora de examinar el contenido de la teoría del derecho acudir a The Concept of Law de Herbert Hart, que es en buena medida una reflexión sobre lo que el derecho es y sobre lo que no es, dirigida a "hacer avanzar la teoría jurídica proporcionando un análisis más elaborado de la estructura de un sistema jurídico, y una mejor comprensión de las semejanzas y diferencias entre el derecho, la coacción y la moral, como tipos de fenómenos sociales". ${ }^{22}$ Ahora bien, es de N. Bobbio de quien podemos obtener una de las mejores respuestas a la cuestión de en qué consiste la teoría del derecho. El italiano asimila la teoría del derecho a una teoría del ordenamiento jurídico, a partir de la idea de que "por "derecho" se entiende no una norma aislada, sino un conjunto de normas y, por tanto, el concepto de derecho sólo puede ser aclarado haciendo referencia no ya a un tipo de norma sino a un tipo de conjunto de normas". ${ }^{23} \mathrm{Y}$ desde este punto de vista, divide la teoría del ordenamiento jurídico en una lista de seis temas, que son los siguientes: "1) composición (concepto de norma y distintos tipos de normas); 2) formación (teoría de las fuentes del derecho); 3) unidad (validez y norma fundamental); 4) plenitud (lagunas y su integración); 5) coherencia (antinomias y

22 Hart, H. L. A., The Concept of Law, Oxford, Oxford University Press, 1961; trad. de Genaro R. Carrió, El concepto de derecho, Buenos Aires, Abeledo-Perrot, 1998, p. 21.

23 Bobbio, N., "Naturaleza y función de la filosofia del derecho", cit., p. 98. 
su eliminación); 6) relaciones entre ordenamientos (relaciones espaciales, temporales y materiales)". ${ }^{24}$

Para el profesor G. Peces-Barba, "la teoría del derecho es el núcleo inicial, y el punto de partida necesario para toda la restante reflexión iusfilosófica, especialmente para la teoría de la justicia", debiéndose ocupar

...del establecimiento del concepto de derecho", lo que "supone tratar al menos los siguientes problemas: 1) Crítica de la dogmática; 2) Relaciones entre derecho y poder; el fundamento último de la validez del derecho; 3) El contenido material del derecho: la ordenación de la vida social humana; 4) El derecho como ordenamiento; 5) Estructura y función del derecho; 6) Conceptos fundamentales del derecho; 7) Distinción de otras materias afines. ${ }^{25}$

Lógicamente, una temática de este tipo significa, por un lado, asumir un punto de vista "normativo" del derecho y, por otro lado, enfocar todos los temas de teoría del derecho a partir de la idea del derecho como "sistema". Es decir, se trata de una perspectiva sistémica del derecho que no plantea problemas a la hora de abarcar el concepto de derecho, y que contempla la teoría de las normas desde una concepción holística. ${ }^{26}$

Por su parte, Alberto Montoro Ballesteros ha distinguido tres lineas de desarrollo de la ontología jurídica, a modo de "tres visiones, tres modos diferentes de comprender y explicar la realidad jurídica (el ser del derecho)". El catedrático de la Universidad de Murcia diferencia, en primer lugar, "La filosofia del derecho como ontología jurídico-material", cuya temática "gira en torno a la pregunta por el contenido sustancial del derecho: lo justo o el derecho justo". En segundo lugar, "La filosofia del derecho como ontología juridi-

24 Ibidem, p. 98.

25 Peces-Barba, G., "La teoría del derecho", Introducción a la filosofía del derecho, cit., p. 265.

26 Bobbio, N., Teoría general del derecho, trad. de E. Rozo, 1a. ed., Madrid, Debate, 1991 (2a. ed., Bogotá, Temis, 2005), p. 153. 
co-formal", cuyo objeto "consiste fundamentalmente en la elucidación y estudio de la estructura y de las formas esenciales, constitutivas del derecho". Y, en tercer lugar, "La filosofia del derecho como ontología juridica integral", que "se trata de la búsqueda, de un intento de integración y síntesis de la ontología jurídico-material y la ontología juridico-formal, poniendo de relieve sus interconexiones y relaciones de interdependencia". ${ }^{27}$

Sin duda, la construcción de la teoría del derecho como campo temático y problemático de la filosofia del derecho exige preguntarnos si es posible distinguirla de la teoría general del derecho. En un principio, la dificultad de deslindar a una de la otra tiene que ver con el hecho de que la teoría del derecho es en sí una teoría "general" sobre el derecho, por lo que habria que analizar si realmente existen diferencias entre ellas. Aquí puede llevar razón N. Bobbio cuando afirma que "sólo una tajante distinción entre filosofia del derecho y ciencia del derecho permite evitar los equívocos de las zonas fronterizas, como es precisamente la teoría general, la cual, cuando la distinción no es tajante, viene a caer en uno u otro territorio según la atraigan intereses prácticos a una parte más que a otra; así se suscitan esos híbridos de filosofias del derecho". ${ }^{28}$ Sí hay que decir que, en general, una buena parte de la doctrina concibe a una y otra materia desde el criterio de la "identificación aproximada". Por lo que no habría, en este sentido flexible, diferencias cualitativas entre ellas.

En relación a esta controversia, para Hans Kelsen el derecho como debe-ser se corresponde con una teoría de la justicia, que es a lo que se restringiría la Filosofia del derecho, mientras que el derecho como ser se equipara con la teoría general del derecho, que incluiria temáticamente una teoría del derecho y una teoría del conocimiento jurídico,

27 Montoro Ballesteros, A., "Ontología jurídica en perspectiva histórica”, Anuario de Filosofía del Derecho, núm, XVI, Revista Oficial de la Sociedad Española de Filosofia Jurídica y Política, Madrid, Ministerio de Justicia, Boletín Oficial del Estado, 1999, p. 287.

28 Bobbio, N., "Naturaleza y función de la filosofía del derecho", cit., pp. 88 y 89. 
ambas de naturaleza cientifica. De modo que según el austriaco, teoría del derecho y teoría general del derecho formarian parte de la misma clase de contenido y de la misma naturaleza científica pero no abarcarian lo mismo. Puede decirse que entre las dos él concibe una relación de "identidad" pero de carácter "asimétrico". Desde la perspectiva de $\mathrm{N}$. Bobbio, que aunque originariamente en la década de los cincuenta $^{29}$ se encontraba más cerca del punto de vista kelseniano y no entendía a la teoría general del derecho como parte de la reflexión iusfilosófica porque le atribuía carácter de teoría formal y científico-jurídico, ${ }^{30}$ su posición posterior prácticamente viene a identificar teoría del derecho y teoría general del derecho como una misma materia temática que se adscribe a la filosofia del derecho. ${ }^{31}$ Pensando, por tanto, la relación entre las dos como una relación de "identidad" de carácter "simétrico". En el mismo sentido, G. Peces-Barba también concibe entre teoría del derecho y teoría general del derecho relaciones de identidad simétricas, y le atribuye a esta temática resultante carácter iusfilosófico porque "pretende establecer el concepto y el significado del derecho, basado por supuesto en la información que proporciona la ciencia, pero con un nivel de abstracción y generalidad, en el marco de la historia y de la cultura jurídica". 32 De modo parecido, Luis García San Miguel también acepta una relación de identidad entre las dos temáticas, pues considera que la teoría del derecho en sentido estricto es la teoría general del derecho, pero en vez de adscribirla al ámbito de la filosofia del derecho lo hace indistintamente a la filosofia del derecho y al campo de la ciencia jurídica, porque esa materia puede tener carácter científico pero también a veces consistir en una reflexión iusfilosófica; y esto

29 Cfr. Guastini, R., "Imágenes de la teoría del derecho", cit., pp. 23 y 24 y 58-77.

30 Bobbio, N., "Filosofia del derecho y teoria general del derecho", Contribución a la teoría del Derecho, cit., pp. 82-86.

31 Bobbio, N., "Naturaleza y función de la filosofía del derecho", cit., pp. 91-101.

32 Peces-Barba, G., Introducción a la filosofía del derecho, cit., p. 185. 
dependerá de la perspectiva adoptada por el investigador que opera con ella. ${ }^{33}$

Al entender de R. Hernández Marín, la filosofia del derecho "tiene sólo dos partes: la teoría general del derecho y la teoría de la ciencia jurídica". ${ }^{34} \mathrm{Y}$ considera a la teoría del derecho un "sustituto ilegitimo" de la teoría general del derecho, ${ }^{35}$ a la que atribuye carácter iusfilosófico. Constatando entre las dos una relación de "asimilación" de la primera hacia la segunda. A continuación, "la teoría general del derecho (TGD) se divide en una teoría general de las normas jurídicas, aisladamente consideradas, y en una teoría general de las relaciones entre normas jurídicas. La primera puede ser llamada "teoría general de las normas jurídicas"; a la segunda se la conoce con el nombre de "teoria del ordenamiento jurídico" o "teoría del sistema jurídico"”. ${ }^{36}$ Eso sí, partiendo de que la teoría del ordenamiento jurídico (TOJ) presupone la teoría general de las normas jurídicas (TGNJ), en mayor medida identifica la ontologia jurídica con la teoría general de las normas jurídicas. ${ }^{37}$

En la disquisición de Manuel Atienza, la teoría general del derecho estudia los conceptos generales y formales del derecho, lo que la distingue de la dogmática jurídica dedicada a configurar conceptos de menor nivel de abstracción, pero su marco temático es interno al derecho dado que no

33 García San Miguel, L., Notas para una critica de la razón jurídica, Madrid, Servicio de Publicaciones de la Facultad de Derecho-Universidad Complutense, 1985, pp. 18-43.

34 Hernández Marín, R., "Concepto de la filosofia del derecho", Anuario de Filosofía del Derecho, núm. X, Revista Oficial de la Sociedad Española de Filosofía Jurídica y Política, Ministerio de Justicia, Madrid, Boletín Oficial del Estado, 1993, p. 176, y que aclara previamente en la p. 175, que "hay dos clases de filosofia jurídica: una relativa a derecho como fenómeno aislado; otra, que lo contempla como un fenómeno social, relacionado con otros fenómenos sociales. La primera relativa al derecho estrictamente, puede ser llamada "filosofia del derecho en sentido estricto" o, simplemente, "filosofia del derecho"; la segunda, que es un aspecto de la filosofia social, que es la reflexión filosófico-social aplicada al derecho, puede ser llamada "filosofia socio-jurídica" (que no debe ser confundida con la sociología jurídica)".

35 Ibidem, pp. 184-186.

36 Ibidem, p. 176.

37 Hernández Marín, R., "Concepto de la filosofia del derecho", cit., pp. 180-182. 
cuestiona el derecho con el que opera, y no tiene por eso carácter iusfilosófico. Sin embargo, la temática de la ontología o teoría del derecho es externa al derecho, porque sí cuestiona el marco del derecho en el que opera, y tiene, en este sentido, carácter iusfilosófico. ${ }^{38}$ Con la misma orientación se ha manifestado Eusebio Fernández. ${ }^{39}$ Por su parte, R. Guastini no contempla más que la teoría del derecho, a la que, por tanto, asimila la teoría general del derecho, e identifica con la filosofia del derecho de los juristas. ${ }^{40} \mathrm{Y}$ habla de la teoría del derecho como teoría "general" en sentido "fuerte" o universal, a la que atribuye "un cierto poso iusnaturalista"; en sentido "débil" o transordinamental "de una serie circunscrita de ordenamientos (coetáneos) que presentan características comunes"; y en sentido "debilísimo" o transectorial "de conceptos y principios comunes a los diversos sectores de un mismo ordenamiento". ${ }^{11}$ Por último, también es de interés la opinión del profesor Ramón Soriano, que asimila el contenido temático de la teoría del derecho a la de teoría general del derecho, prefiriendo esta terminología, y atribuyéndola al ámbito de la filosofía del derecho, dada "la abundancia de estudios sobre los diversos campos de la teoría general del derecho positivo producidos por profesores e investigadores españoles del área de Filosofía del derecho, siguiendo la práctica común e inveterada de profesores e investigadores de otras latitudes". ${ }^{42}$

un segundo ámbito temático de la filosofía del derecho de los juristas ha sido confeccionado contemporáneamente como "gnoseología jurídica" o "epistemología jurídica": la teoría de la ciencia jurídica, cuyo objeto cognoscitivo versa sobre los métodos de conocimiento del derecho. En palabras de N. Bobbio, la teoría de la ciencia jurídica consiste

38 Atienza, M., Introducción al derecho, Barcelona, Barcanova, 1994, p. 369.

39 Fernández, E., Estudios de ética jurídica, Madrid, Debate, 1990, p. 27.

40 Guastini, R., "Imágenes de la teoría del derecho", cit., pp. 17-19.

41 Ibidem, pp. 22 у 23.

42 Soriano, R., Compendio de teoría general del derecho, 2a. ed. corregida y aumentada, Barcelona, Ariel, 1993, pp. 11-26. 
en el "estudio de los procedimientos intelectuales adoptados por los juristas para determinar, interpretar, integrar y conciliar entre sí las reglas de un sistema jurídico". ${ }^{43}$ Vendría a corresponderse con lo que tradicionalmente se ha identificado como "teoría del conocimiento jurídico", o "lógica jurídica", o "metodología jurídica", o "metajurisprudencia", aun cuando, como afirma el profesor Jesús Vega, la terminología teoría de la ciencia jurídica "puede considerarse consolidada desde la mitad del pasado siglo a partir de trabajos clásicos como los de Cairns (1941) o Bobbio (1950)".44 En relación a esto, hay que tener en cuenta que la Filosofia del derecho se ha ocupado del análisis del conocimiento jurídico, sobre todo a partir del siglo XIX en cuanto se produjo la separación entre filosofía y ciencia promovida por las concepciones positivistas. Aunque, las relaciones entre "ciencia" (jurídica: jurisprudencia) y "teoría de la ciencia" (jurídica: metajurisprudencia) son complejas y dependen de cuál es la naturaleza de la ciencia jurídica, pues no siempre es la misma, y cuál es la concepción de la ciencia general o jurídica que sostiene a la metajurisprudencia. ${ }^{45}$

En opinión de R. Hernández Marín, la teoría de la ciencia jurídica es "un tema central de la filosofia jurídica, conforme a una tradición filosófica (tanto en el ámbito de la filosofía general, como en el más estricto de la filosofia jurídica) y conforme, especialmente, a la filosofia contemporánea, que ha sido y es en gran medida filosofia de la ciencia". E identifica ciencia jurídica con dogmática jurídica, "que se ocupa del derecho, no como fenómeno social, sino como un fenómeno aislado, [por lo que] se puede decir que, al estudiar la ciencia jurídica, la filosofia del derecho tiene que ver, aunque sólo de forma indirecta, con el derecho como fenómeno

43 Bobbio, N., "Naturaleza y función de la filosofía del derecho", cit., p. 99.

44 Vega, J., "El lugar de la teoría de la ciencia jurídica en la filosofia del derecho", en varios autores, Teoría y metodología del derecho. Estudios en homenaje al profesor Gregorio Peces-Barba, Madrid, Dykinson, 2008, 4 vols., vol. II, p. 1.167, prefiere la terminología de epistemología jurídica.

45 Bobbio, N., "Ser y deber ser en la ciencia jurídica", Contribución a la teoría del derecho, cit., pp. 201-204. 
aislado". Y de cara a la formación del jurista, "la importancia de la TCJ [teoría de la ciencia jurídica], concebida del modo descrito, reside en que esta materia es lo que permite al jurista tomar conciencia de su propia actividad, de su propio discurso acerca del derecho". ${ }^{46}$ Según H. Kelsen, "la ciencia del derecho sólo puede describir el derecho; no puede, a diferencia del derecho producido, en normas generales e individuales, por la autoridad jurídica, prescribir algo". Además, "la ciencia del derecho es conocimiento de éste, no conformación del mismo. Pero en la jurisprudencia tradicional reina la tesis de que la ciencia del derecho puede y debe también actuar como conformadora del derecho". Sin embargo, para el jurista austriaco esto supone una confusión entre ciencia y política jurídica. 47

Como parte integrante de la filosofia del derecho, la teoría de la ciencia jurídica participa de sus mismas características, por lo que se trata de una reflexión iusfilosófica y de un saber jurídico centrado en los problemas sobre el conocimiento del derecho. Tal como he referido y afirma G. Peces-Barba, "la filosofia del derecho no se puede construir al margen de la ciencia jurídica, ni prescindiendo de ella". Se trata de "una reflexión que podemos calificar de descriptiva y crítica al mismo tiempo, asumiendo con la calificación de crítica" la posibilidad "de que la teoría de la ciencia jurídica —que Bobbio llama también metajurisprudencia-, pueda ser prescriptiva”. Y cuya concreción temática debe incluir los siguientes "escalones de reflexión sucesivos": 1) Los problemas generales; 2) La historia de la ciencia jurídica y de su teoria; 3) La materia y la finalidad de la ciencia jurídica; 4) La fundamentación científica del conocimiento jurídico; y 5) El carácter de la Teoría de la ciencia jurídica". 48

46 Hernández Marín, R., "Concepto de la filosofia del derecho", cit., p. 182.

47 Kelsen, H., Teoría pura del derecho [1934 y 1960], traducción española de la 2a. ed. alemana de Roberto J. Vernengo, México, Porrúa, 1993.

48 Peces-Barba, G., "La teoría de la ciencia jurídica", Introducción a la filosofía del derecho, cit., pp. 281 y 283. 
En la visión del profesor Jesús Vega, la teoría de la ciencia jurídica abarca "cuatro ámbitos de problemas abiertos a la filosofia del derecho - en cuanto reflexión totalizadora sobre la experiencia jurídica- cuya dilucidación es de naturaleza formalmente epistemológica o perteneciente a una teoría de la ciencia jurídica", y que pueden agruparse "en las dos rúbricas siguientes: conocimiento en el derecho y conocimiento sobre el derecho". Respecto al conocimiento "en" el derecho, la epistemología jurídica "se configura como una "metametodología" de la praxis jurídica", y consiste en

...una reflexión sobre la estructura conceptual y metodológica del derecho mismo en tanto normatividad abstracta de dimensión material y formal ("nomoestática", law in books, lado pasivo) y normatividad pragmáticamente operativa en el curso del proceso ejecutivo de los decisores jurídicos legislativos y jurisdiccionales ("nomodinámica", law in action, lado activo).

Respecto al conocimiento "sobre" el derecho, la epistemología jurídica está centrada en

...aclarar las relaciones existentes entre los conceptos de "derecho" y "ciencia", así como la problemática general de las ciencias jurídicas —organización y unidad interna, división y clasificación, principios y métodos, arquitectura teórica, etc.- serian las cuestiones fundamentales aquí abiertas a la filosofia jurídica qua análisis ahora "metacientífico".

En relación a la dogmática, este planteamiento crítico "se concreta en dos frentes principales de problemas. El primero tiene que ver con las relaciones entre la dogmática y su objeto, el propio derecho - lo que podemos llamar su estatuto interno- y debe determinar las razones que hacen que esta disciplina haya asumido desde siempre el papel de ciencia "esencial" o por autonomasia del derecho"; y el segundo, "se plantea las relaciones entre la dogmática y otras 
ciencias (estatuto externo) para preguntarse no ya si es disciplina jurídica sino si es científica". ${ }^{49}$

Según R. Hernández Marín, "los mismos [temas] en que se divide la filosofia de la ciencia, en la medida en que sean trasladables de un ámbito [filosofía de la ciencia] a otro [ámbito jurídico]", son predicables de la teoría de la ciencia jurídica, que

...analiza los enunciados de la ciencia del derecho, tanto aisladamente como en sus relaciones recíprocas. El estudio de los enunciados científico-jurídicos aislados conduce a temas tan importantes como la interpretación del derecho y la aplicación del derecho. El análisis de las relaciones, concretamente relaciones lógicas, existentes entre los enunciados científico-jurídicos conduce, por ejemplo, al estudio de la lógica, la axiomatización de teorías jurídicas y, eventualmente, a plantear la posibilidad de lógicas o formas de argumentación alternativas a la lógica. ${ }^{50}$

Aquí hay que tener en cuenta que la descripción de la realidad jurídica que lleva a cabo la ciencia jurídica a modo de dogmática tiene consecuencias en la práctica jurídica y en este sentido afecta a las decisiones sobre los derechos y libertades fundamentales de la gente. Circunstancia que obliga a no olvidar que es necesario prestar atención al parámetro ideológico que está implícito en la forma de ver las cosas (jurídicas) por parte de la dogmática. Correspondiendo a la filosofia del derecho, en su función de "teoría crítica del derecho", desenmascarar cuál es ese criterio ideológico con el que está operando la dogmática en cada momento, y que se encuentra condicionando sus postulados y conclusiones. Algo que habrá que observar cuando se analice su estatuto epistemológico. ${ }^{51} \mathrm{G}$. Peces-Barba ha recalcado este

49 Vega, J., "El lugar de la teoría de la ciencia jurídica en la filosofia del derecho", cit., pp. 1.173-1.174 y 1.176-1.178.

50 Hernández Marín, R., “Concepto de la filosofia del derecho”, cit., p. 182.

51 Calsamiglia, A., Introducción a la ciencia jurídica, Barcelona, Ariel, 1990, pp. 140-143. 
aspecto de crítica a la dogmática como función principal de la filosofia del derecho. ${ }^{52} \mathrm{Y}$ en la misma dirección también se ha pronunciado Antonio Enrique Pérez Luño ${ }^{53}$ o la profesora Marina Gascón, según la cual la filosofía del derecho debe de operar "asumiendo una labor crítica del derecho y del saber dogmático que permita la formación de un jurista capaz de abrir su mente más allá de la normatividad empírica". 54

Posiblemente una de las temáticas más relevantes en las que se adentra la teoría de la Ciencia jurídica consiste en determinar el estatuto gnoseológico del conocimiento jurídico, a fin de poder juzgar si el conocimiento jurídico tiene o no tiene carácter científico. Esta cuestión es muy discutida en la doctrina. A las posiciones que atribuyen carácter científico al conocimiento jurídico pertenece la opinión de $\mathrm{H}$. Kelsen. El carácter normativo de la ciencia jurídica es susceptible de predicarse en los tres siguientes sentidos: en relación con su objeto, con su método y con su función. La ciencia jurídica es normativa en el primer sentido si su objeto está compuesto por normas; es normativa en el segundo sentido si describe su objeto mediante proposiciones normativas; y, por último, es normativa en el tercer sentido si su función consiste en prescribir comportamientos o proponer normas. ${ }^{55}$ Pues bien, para H. Kelsen, la ciencia jurídica, que debe expresarse mediante proposiciones normativas que constituyen el tipo de lenguaje apropiado para

52 Peces-Barba, G., "La necesidad y la justificación de la filosofia del derecho: la crítica de la Dogmática jurídica”, Introducción a la filosofía del derecho, cit., pp. 187-206.

53 Pérez Luño, A.E., "La filosofía del derecho y la formación de los juristas", Sistema, Madrid, 1982, núm. 49, pp. 90-93.

54 Gascón Abellán, M., "Consideraciones sobre el objeto de la filosofía jurídica", Anuario de Filosofía del Derecho, núm. X, Revista Oficial de la Sociedad Española de Filosofia Jurídica y Política, Ministerio de Justicia, Madrid, Boletín Oficial del Estado, 1993, p. 193.

55 Ross, A., Sobre el derecho y la justicia, cit., pp. 32 y 33; asimismo, vid. Bobbio, N., "Ser y deber ser en la ciencia jurídica", cit., pp. 197-200. 
describir normas, tiene carácter "normativo" en los dos primeros sentidos, pero no lo tiene en el tercer sentido. 56

De entre las posiciones que no atribuyen carácter científico a la Dogmática jurídica podemos remontarnos a J.H.v. Kirchmann. ${ }^{57}$ Pero también Alf Ross ha discutido la noción de "normatividad" como objeto de la ciencia jurídica, para proponer una ciencia realista del derecho. ${ }^{58}$ Desde su consideración, la Filosofia del derecho no debe tener por objeto al derecho, porque de éste se ocupa ya la ciencia jurídica, ni tampoco a la axiología jurídica puesto que se trata de un sin sentido; sino que debe centrarse en el análisis de la ciencia del derecho. Dicho con sus palabras: "la filosofia del derecho dirige su atención hacia el aparato lógico de la ciencia del derecho, en particular hacia el aparato de conceptos", por lo que "El objeto de la filosofia del derecho no es el derecho, ni parte o aspecto alguno de éste, sino la ciencia del derecho. La filosofía del derecho está, por así decir, un piso más arriba que la ciencia del derecho y la mira "desde arriba". 59

R. Guastini comparte aproximadamente este planteamiento, entendiendo que la teoría del derecho, que es filosofia del derecho de los juristas, no es sino la filosofia de la ciencia jurídica, o de la dogmática, y su instrumento básico es el análisis lingüístico. El objeto de la filosofía del derecho es, pues, la dogmática y no el derecho, que sí es el objeto de la dogmática: "La línea de demarcación de las dos disciplinas puede ser clarificada con una simple noción lógica: la dogmática y la teoría del derecho se colocan en dos niveles del lenguaje distintos". Si el derecho es "un

56 Kelsen, H., Teoría pura del derecho, cit., pp. 84-88.

57 Véase Kirchmann, J. H. v., La jurisprudencia no es ciencia, trad. De A. Truyol y Serra, Madrid, Centro de Estudios Políticos y Constitucionales, 1985.

58 Véase Ross, A., Hacia una ciencia realista del derecho. Crítica del dualismo en el derecho, trad. De J. Barboza, Buenos Aires, Abeledo-Perrot, 1961, pp. 120 y 121; asimismo véase Ross, A., "Nota al libro de Kelsen ¿Qué es la justicia?", El concepto de validez y otros ensayos, trad. de G. R. Carrió, México, Fontamara, 2001, pp. 40 y 41.

59 Ross, A., Sobre el derecho y la justicia, cit., p. 49. 
lenguaje", entonces la dogmática tiene por objeto el "discurso del legislador" (el derecho), y la teoría del derecho se ocupa "del discurso de la propia dogmática". 60 Según el profesor de Génova, existen dos formas, tendencias o estilos de hacer teoría de la ciencia jurídica. Por un lado, desde el punto de vista "externo" a la ciencia jurídica, consistente en la descripción de la dogmática actual pero "sin inmiscuirse en las controversias entre juristas, sino únicamente arrojando luz sobre los aspectos prácticos (por ejemplo, proyectando luz sobre los presupuestos ideológicos y las implicaciones políticas de las tesis en conflicto)". Este tipo de teoría de la ciencia jurídica es meramente "descriptiva". ${ }^{61}$ Aquí la teoría de la ciencia jurídica tiene por objeto normas y, por consiguiente, sus enunciados son "proposiciones acerca de normas". Se tratas de una concepción normativista de la ciencia jurídica que genera una teoría de la ciencia jurídica "descriptiva". ${ }^{62}$ Opuestamente, la otra forma de hacer teoría de la ciencia jurídica es desde el punto de vista "interno" a la ciencia jurídica, consistente en inmiscuirse en las controversias entre juristas, "proponiendo, por ejemplo, redefiniciones de los conceptos discutidos; redefiniciones destinadas, inevitablemente, a incidir sobre la interpretación de los documentos normativos". Esta segunda forma de hacer teoría de la ciencia jurídica deriva hacia la propia dogmática para constituir una especie de "alta dogmática". ${ }^{63}$ Aquí la teoría de la ciencia jurídica, que es una concepción conductista (no-normativa) de la misma, tiene por objeto comportamientos humanos, en el sentido de "comportamientos productores de normas y/o guiados por normas", y a este respecto sus enunciados expresan "proposiciones empíricas ordinarias". La concepción conductista de la ciencia jurídica tiende a generar una teoría de la ciencia jurídica "prescrip-

60 Guastini, R., "Imágenes de la teoría del derecho", cit., p. 27.

61 Ibidem, pp. 27 y 28.

62 Guastini, R., "Los juristas a la búsqueda de la Ciencia", Distinguiendo. Estudios de teoría y metateoría del derecho, cit., pp. 263 y 264.

63 Guastini, R., "Imágenes de la teoría del derecho", cit., pp. 27 y 28. 
tiva", cuya función es la de reconstruir la dogmática jurídica. 64

Es discutible si ambos tipos de ciencia jurídica, la dogmática como teoria "descriptiva" y la alta dogmática como teoría "prescriptiva" de la ciencia jurídica, cumplen el estatuto epistemológico del conocimiento científico, o se trata más bien de reflexiones filosóficas meramente especulativas. En este ámbito, el profesor Albert Calsamiglia se ha decantado por una teoría de la ciencia jurídica que sea "descriptiva", que trate de "describir el funcionamiento de la comunidad dogmática". 65 Ahora bien, que sea una teoría descriptiva no cierra la cuestión, que entonces se va a replantear en términos de si la dogmática jurídica consiste en el conocimiento "científico" o se reduce a un mero conocimiento "técnico" del derecho. Pregunta que nos lleva a examinar lo que en realidad proporciona la dogmática jurídica. En este campo, al igual que J.H.v. Kirchmann, R. Guastini niega el carácter científico de la dogmática, en virtud de que "los juristas omiten comportarse como científicos (en el sentido común del término) y se comportan como fuentes del derecho. Bajo esta perspectiva, no parece ser adecuado para la jurisprudencia el nombre de "ciencia" del derecho, ya que es indistinguible de la politica del derecho". 66 Para Manuel Atienza, la dogmática jurídica es una técnica, no es una ciencia: "su objetivo no es el de conocer por conocer, sino el de conocer para actuar, para permitir la realización y evolución del derecho positivo", 67 y como tal técnica la dogmática no es concebible sin tener en cuenta las decisiones jurídicas.

Finalmente, en la filosofia del derecho de los juristas también se ha conformado un tercer ámbito temático: la teoría de la justicia, construido como "ética normativa" o "axiología jurídica" según la denominación utilizada por el

64 Guastini, R., "Los juristas a la búsqueda de la Ciencia”, cit., pp. 263 y 264.

65 Calsamiglia, A., Introducción a la ciencia jurídica, cit., p. 17.

66 Guastini, R., "Los juristas a la búsqueda de la ciencia”, cit., p. 274.

67 Atienza, M., Introducción al derecho, cit., p. 249. 
profesor Elías Díaz. ${ }^{68}$ Este campo temático de la Filosofia del derecho de nuestro tiempo interesa a todo jurista que asume que ineludiblemente el fin principal que persigue el derecho no puede ser otro que la justicia. Su objeto cognoscitivo, por tanto, es la justicia como fin del derecho. En virtud de este objeto cognoscitivo centrado en los valores del derecho, ${ }^{69}$ dicha dimensión temática también ha sido denominada "ética jurídica" o incluso "filosofia del derecho socio-politica" como la califica R. Hernández Marín. ${ }^{70} \mathrm{Y}$ tiene como presupuestos, por un lado, la afirmación de que es posible y deseable la relación entre derecho y justicia. Por otro lado, que la justicia es el valor más importante del derecho. Y, por último, que en el razonamiento jurídico tiene cabida el razonar sobre valores y el enjuiciar desde ellos al derecho positivo. En palabras de G. Peces-Barba, la teoría de la justicia "tiene la función de reflexionar críticamente sobre los valores del derecho positivo y proponer otros valores distintos, en su caso, para transformar los ideales jurídicos de ese ordenamiento jurídico positivo", nucleándose, por tanto, su reflexión en "el derecho que debe ser, en los elementos de moralidad que debe contener un ordenamiento". ${ }^{71}$

Como parte integrante de la filosofia del derecho, la teoría de la justicia participa de sus mismas características, por lo que se trata de un saber jurídico centrado en "problemas" relacionados con los valores en el derecho. Pero, sobre todo, la teoría de la justicia resalta porque constituye el campo temático más nítidamente crítico de la filosofia del derecho. Hay que decir que este espacio temático de la filosofia del derecho ha experimentado un gran auge a partir del constitucionalismo contemporáneo, con la incorporación a nuestras Constituciones de normas con contenido moral, sea el

68 Díaz, E., Sociología y filosofía del derecho, cit., p. 255.

69 Bobbio, N., "Naturaleza y función de la filosofia del derecho", cit., p. 98.

70 Hernández Marin, R., Introducción a la teoría de la norma jurídica, Madrid, Marcial Pons, 1998, p. 16.

71 Peces-Barba, G., "La teoría de la justicia: el derecho natural y los derechos fundamentales", Introducción a la filosofía del derecho, cit., p. 305. 
caso de las que reconocen valores, o proclaman principios o establecen derechos y libertades fundamentales. Valores, principios y derechos, hoy constitucionalmente juridificados, que representan el ámbito de la teoría de la justicia imperante en un ordenamiento jurídico. Tal como dice Luigi Ferrajoli, ahora "la diferencia entre ser y deber ser del derecho expresado por la vieja dicotomía ley positiva/ley natural se ha transformado en gran medida en una diferencia entre ser y deber ser en el derecho, trasladándose al tejido mismo de los ordenamientos jurídicos positivos y configurándose como incoherencia o antinomia entre sus diferentes niveles normativos", a consecuencia de lo cual el autor italiano ha distinguido entre "validez formal" (o vigencia) y "validez sustancial" de las normas. ${ }^{72}$ Claro está, en la medida en que el resto de normas deben ajustarse a esas normas constitucionales de contenido moral los juicios internos de validez normativa exigirán a los juristas desplegar "argumentaciones" también de carácter moral en las que tendrán que manejar y conformar decisiones racionales sobre valores. Con el constitucionalismo actual, la teoría de la justicia ha pasado de realizar anteriormente desde el ámbito de los valores una función de enjuiciamiento "extrajurídico" al derecho a llevar ahora a cabo un enjuiciamiento "intrajurídico" al derecho desde el propio ámbito interno del derecho (fundamentalmente en el nivel constitucional) incorporador de valores morales. De modo que si antes la teoría de la justicia era algo más bien ajeno a la dogmática jurídica, ahora se presenta como una actividad necesaria de la propia dogmática jurídica crítica.

En cualquier caso, además de lo que se ha mencionado en relación al constitucionalismo en nuestro tiempo (defini-

72 Ferrajoli, L., Derecho y razón. Teoría del garantismo penal, trad. de P. Andrés Ibáñez, A. Ruiz Miguel, J.C. Bayón Mohino, J. Terradillos Basoco, R. Cantarero Bandrés, Madrid, Trotta, 1997, pp. 356 y 357; véase asimismo Zagrebelsky, G., El derecho dúctil, trad. de Marina Gascón, epílogo de Gregorio Peces-Barba, Madrid, Trotta, 1995, p. 116, para quien la relación entre ley y Constitución es muy similar a la de ley y derecho natural, y la argumentación constitucional -y en mayor medida la que llevan a cabo los Tribunales Constitucionales- se asemeja al modo de argumentar en derecho natural. 
do a menudo como neoconstitucionalismo ${ }^{73}$ ), la justicia se presenta como un "valor jurídico" desde el momento en que consideramos al derecho el instrumento social por excelencia para realizar los valores de justicia y por el hecho de que no es posible imaginar una sociedad justa sin derecho. Asumir que un sector temático de la Filosofía del derecho se corresponde con la teoría de la justicia no quiere decir, en definitiva, sino que el derecho como tal puede ser evaluado en términos de su razonabilidad o irracionalidad. La reflexión sobre el derecho justo, como afirma Luis Prieto Sanchís, se traduce en este sentido en "abrirse al mundo de la legitimidad y de los valores",74 y en afirmar que existe, por consiguiente, una "conexión" entre el derecho y la justicia que no es posible ni deseable obviar.

Ya sea como una exigencia externa o interna a lo jurídico, la idea de justicia en el derecho la concibe N. Bobbio en un sentido amplio, definiéndola como "el conjunto de los valores, bienes o intereses para cuya protección o incremento los hombres recurren a esa técnica de convivencia a la que solemos dar el nombre de derecho". ${ }^{75}$ Elías Díaz define la axiología jurídica como el "enjuiciamiento crítico del derecho positivo desde un determinado sistema de valores; pero también, [la] confrontación racional y [el] análisis crítico de los diferentes posibles sistemas de valores que, de modo sucesivo (diacrónico) y simultáneo (sincrónico) tratan de presentarse como legítimos o justos"; axiología jurídica, a la que estima "una parte de la ética: como ética jurídica o análisis crítico de los valores jurídicos, teoría de la justicia principalmente, pero incluyendo también a los demás valores: libertad, paz, igualdad, etc.".76

73 Véase Carbonell, M. (coord.), Teoría del neoconstitucionalismo: ensayos escogidos, Madrid, Trotta, 2007.

74 Prieto Sanchís, L., "Un punto de vista sobre la filosofia del derecho", Anuario de Filosofía del Derecho, núm. IV, Revista Oficial de la Sociedad Española de Filosofia Jurídica y Política, Ministerio de Justicia, Madrid, Boletín Oficial del Estado, p. 606.

75 Bobbio, N., "Naturaleza y función de la filosofia del derecho", cit., p. 98.

76 Díaz, E., Sociología y filosofía del derecho, cit., p. 255. 
En relación con la ubicación de la teoría de la justicia en el ámbito de la filosofía del derecho, la posición actual más aceptada es que por su dimensión crítica ocupa un lugar central. Así lo pone de manifiesto G. Peces-Barba, para quien

...hay coincidencia generalizada, incluso con evolución en los ambientes neopositivistas y analíticos, como lo prueba la obra de Hart [...] en la existencia de una reflexión, parte central, y, en algunos supuestos, única, de la Filosofia del derecho, sobre los valores jurídicos, el derecho justo, el derecho que debe ser, o la moralidad del derecho. ${ }^{77}$

También para A. Kaufmann la teoría de la justicia es el tema nuclear de la filosofía del derecho, y de hecho considera que "las dos preguntas fundamentales de la filosofía del derecho [precisamente] son: 1) qué es el derecho justo, y 2) cómo lo reconocemos". 78 Según Marina Gascón, "una filosofía del derecho, incluso entendida de un modo riguroso, no puede abdicar de lo que generalmente se llama teoría de la justicia, pues tanto el análisis del lenguaje del derecho como el del lenguaje de los juristas - que a veces se confunden-desemboca en una reflexión acerca de la argumentación jurídico-moral y, a la postre, acerca del modo de legitimidad". 79

Con la misma orientación, M. Atienza afirma que "lo que da sentido al derecho - y a ocuparse profesionalmente del derecho- no puede ser otra cosa que la aspiración a la justicia o, para decirlo en términos más modestos y más realistas: la lucha contra la injusticia". 80 Ahora bien, esta relevancia temática de la teoría de la justicia en la filosofía del derecho no ha sido siempre así, tal como constató N. Bob-

77 Peces-Barba, G., Introducción a la filosofía del derecho, cit., p. 251.

78 Kaufmann, A., "Teoría de la justicia. Un ensayo histórico-problemático", Anales de la Cátedra Francisco Suárez, Granada, núm. 25, 1985, pp. 37 y ss.

79 Gascón Abellán, M., "Consideraciones sobre el objeto de la filosofia jurídica", cit., p. 213.

80 Atienza, M., El sentido del derecho, cit., p. 312. 
bio en la década de los sesenta del siglo XX: "mientras los estudios de teoría del derecho han hecho notables progresos en estos últimos años, la teoria de la justicia ha sido olvidada". ${ }^{81} \mathrm{Y}$, desde luego, además del neoconstitucionalismo, del auge temático experimentado por la teoría de la justicia en la filosofia del derecho de las últimas décadas hay que hacer también responsable a la excelente difusión alcanzada por la obra teoria de la justicia de John Rawls. ${ }^{82}$ De cualquier modo, esta ubicación tan relevante de la teoría de la justicia en la filosofia del derecho, según José Delgado Pinto, no viene sino a enlazar coherentemente nuestra materia con una tradición que "dio sentido al jusnaturalismo como modo de pensamiento jurídico que cruza la historia intelectual de Occidente". 83

\section{CONCLUSIÓN}

De lo dicho sobre cómo se ha configurado contemporáneamente el contenido temático, problemático, cognoscitivo e investigador de la filosofia del derecho de los juristas se pueden obtener algunas conclusiones relevantes:

I. La filosofia del derecho de los filósofos constituye un "reduccionismo" de lo jurídico que deslegitima, por falta de interés, a la reflexión filosófico-jurídica ante la comunidad de juristas. La razón es que se trata de una mera "filosofia aplicada" de una filosofia general, elaborada más bien por filósofos (no por juristas) que (lógicamente) no conocen en absoluto el derecho o lo conocen muy poco. En cambio, en la filosofia del derecho de los juristas la especulación filosófico-jurídica tiene como punto de partida no la filosofia sino la "experiencia jurídica" y el material aportado por la ciencia del derecho. Se corresponde, pues, con la reflexión teó-

81 Bobbio, N., "Naturaleza y función de la filosofia del derecho", cit., p. 98.

82 Rawls, J., Teoría de la justicia, trad. de. M. D. González, México, Fondo de Cultura Económica, 2002.

83 Delgado Pinto, J., "Los problemas de la filosofia del derecho en la actualidad", cit., p. 26. 
rico-jurídica en la que los filósofos del derecho actúan sino como teóricos del derecho, no existiendo diferencia alguna entre la tarea realizada de un modo y de otro. Por el contrario, entre dichas labores se abriría una brecha importante si lo que comparamos es la filosofia del derecho de los filósofos y la tarea de los juristas. Muy posiblemente está cargado de razón Ricardo Guastini cuando afirma que la filosofía del derecho de los juristas es hoy (al menos terminológicamente) equiparable a la teoría del derecho concebida en un sentido amplio.

II. A la hora de definir el "contenido" de la filosofía del derecho de los juristas no puede prescindirse (y hay que tomarla como punto de partida) de la triada temática de $\mathrm{N}$. Bobbio. Respecto al ámbito de la ontología juridica o teoría del derecho en sentido estricto no parece haber muchas diferencias con la teoría general del derecho, y se reconoce entre ellas una identidad prácticamente simétrica. Su ubicación es más polémica porque mientras que la teoría del derecho (ontología jurídica) es un caso claro de una materia integrante de la filosofía del derecho de los juristas, la teoría general del derecho aparece como una materia "fronteriza" entre dicha filosofia jurídica y la ciencia jurídica positiva. Por lo que muy posiblemente caerá en un lado o en el otro dependiendo de las intenciones del jurista o investigador que opera con ella.

III. En la construcción del ámbito temático de la teoría de la ciencia jurídica la atención que hoy se focaliza hacia la toma de decisiones juridicas pondría de manifiesto la necesidad de ampliar la temática propia de este campo cognoscitivo (integrante de la filosofia del derecho de los juristas) a la materia de argumentación jurídica. Cuatro razones sostienen lo anterior. En primer lugar, la teoría de la ciencia jurídica alcanza en la actualidad una importante dimensión como materia "argumentativa", sobre todo y de modo imprescindible en el tratamiento y resolución de los casos dificiles (hard cases) por los jueces, pero también en el ámbito 
de la legislación (teoría de la legislación). En segundo lugar, como afirma la profesora M. Gascón, la atribución de validez a una norma jurídica ya no puede estimarse como una cuestión únicamente formal de procedimiento y competencia del órgano, sino también como

...un problema sustantivo que requiere interrogarse sobre el contenido de dicha norma a la luz de todo un horizonte de valores plasmados en la Constitución; y, por consiguiente, la labor del jurista, sobre todo en los casos dificiles, no se limitará a una constatación de esos aspectos formales, sino que requerirá el desarrollo de toda una argumentación a partir de principios de moralidad. ${ }^{84}$

De modo que es perfectamente admisible equiparar la racionalidad de la ciencia jurídica con la racionalidad de sus argumentos, esto es, con la posibilidad de comprobar los argumentos de las decisiones jurídicas con reglas de argumentación racional, lo cual nos deriva hacia las teorias de la argumentación jurídica. En tercer lugar, la argumentación jurídica podría desarrollar en el ámbito de la dogmática jurídica tres funciones principales: orientar la producción de normas, orientar la aplicación de las normas y sistematizar el ordenamiento jurídico o un sector de éste. 85 Y, por último, en cuarto lugar, si consideramos a la dogmática jurídica como una técnica sofisticada de interpretación, y si esa actividad (la posibilidad de evaluar la corrección de las decisiones jurídicas en la interpretación) tiene que ver con el uso correcto de las reglas de la argumentación, puede concluirse que parece muy razonable que la teoría de la argumentación jurídica sea considerada parte de la teoría de la ciencia jurídica.

84 Gascón Abellán, M., "Consideraciones sobre el objeto de la filosofía jurídica", cit., pp. 212 y 213.

85 Véase Atienza, M., Las razones del derecho. Teorias de la argumentación juridica, Madrid, Centro de Estudios Políticos y Constitucionales, 1991. 
IV. Finalmente, el ámbito de la teoría de la justicia aparece contemporáneamente como una temática ciertamente consolidada en el campo cognoscitivo de la filosofia del derecho de los juristas, sin embargo es posible distinguir dos grandes posicionamientos (y algunas sub-visiones) en la doctrina acerca de esta cuestión:

1) Las posiciones que han negado la posibilidad de llevar a cabo un discurso racional sobre valores y no admiten que sea posible una teoría de la justicia, porque entienden que no hay ningún tipo de conexión entre el derecho y la moral. Aquí podemos ubicar representativamente al positivismo estricto de Hans Kelsen, 86 y también al realismo jurídico, para quien, en la concepción de Alf Ross: "aplicadas para caracterizar un regla general o un orden, las palabras "justo" e "injusto" carecen de significado", e "Invocar la justicia es como dar un golpe en la mesa: una expresión emocional que hace de la propia exigencia un postulado absoluto", de modo que "Es imposible tener una discusión racional con alguien que apela a la "justicia"".87 Claro está, las posiciones que niegan la posibilidad de llevar a cabo cualquier tipo de discurso racional sobre valores son vulnerables a derivar hacia el positivismo ideológico y el "modelo de jurista acrítico" que proporciona la dogmática.

2) Las posiciones que afirman la posibilidad de llevar a cabo un discurso racional sobre valores y admiten que epistemológicamente se puede articular un razonamiento sobre valores, o sea, un discurso racional sobre la justicia, porque entienden que existe una conexión entre el derecho y la moral. Planteamientos en los que a su vez habría que diferenciar tres sub-posiciones contemporáneas:

86 Kelsen, H., Teoría general del derecho y del Estado, trad. de E. García Máynez, México, UNAM, 1988, p. 15; asimismo, Kelsen, H.: ¿Qué es justicia?, trad. de A. Calsamiglia, Barcelona, Ariel, 2003, p. 35: "ninguna otra cuestión se ha debatido tan apasionadamente, ninguna otra cuestión ha hecho derramar tanta sangre y tantas lágrimas, ninguna otra cuestión ha sido objeto de tanta reflexión para los pensadores más ilustres".

87 Ross, A., Sobre el derecho y la justicia, cit., p. 267. 
2.a) Las posiciones que estiman que esa conexión entre derecho y moral existe pero es "aleatoria". Estas posiciones sería las propias del positivismo jurídico como el "soft positivism" de H. L. A. Hart o el positivismo "inclusivo" o incorporacionista de Jules Coleman.

2.b) Las posiciones que conciben que esa conexión entre derecho y moral es "necesaria" y (tiene naturaleza) "procedimental". Por ejemplo, esta es la perspectiva que mantiene un positivismo jurídico "corregido" como el de Gregorio Peces-Barba, y su idea de justicia procedimental en el derecho en el ámbito de la modernidad a partir de los valores fundamentadores de los derechos. 88 Según el catedrático de la Universidad Carlos III, asumir la positividad del derecho debe significar inmediatamente asumir la "crítica" a la positividad si no queremos acomodarnos a una relación derecho/poder que sea expresión del más fuerte. ${ }^{89}$ La fidelidad al positivismo no le impide a G. Peces-Barba poder afirmar que los valores superiores del ordenamiento jurídico son "la cabeza de la constitución material", y que éstos se corresponden con una "teoría material de la justicia sin necesidad de sostener posiciones iusnaturalistas".90 Como la teoría de la justicia debe de establecer cuáles son los valores que la integran y qué relaciones existen entre ellos, desde la perspectiva del positivismo corregido los derechos humanos constituyen el contenido material de la justicia que es propia de nuestro tiempo. ${ }^{91}$ Son, en este sentido, el criterio último de enjuiciamiento de la legitimidad de un sistema jurídico, y concretan los valores de libertad, igualdad, seguridad y solidaridad sustentados en

88 Peces-Barba, G., "Desacuerdos y acuerdos con una obra importante", Derechos sociales y positivismo jurídico (Escritos de filosofía jurídica y politica), Madrid, Dykinson, Instituto de Derechos Humanos Bartolomé de las Casas, Universidad Carlos III de Madrid, 1999, pp. 125-130.

89 Peces-Barba, G., Introducción a la filosofía del derecho, cit., p. 192.

90 Peces-Barba, G., Los valores superiores, Tecnos, Madrid, 1984, pp. 89 y 101.

91 Peces-Barba, G., Introducción a la filosofía del derecho, cit., p. 329. 
el principio de la dignidad humana. ${ }^{92}$ La libertad, la igualdad, la seguridad y la solidaridad como valores ético-jurídicos superiores es la propuesta de teoría de la justicia que adopta el positivismo corregido de G. Peces-Barba. ${ }^{93}$

Aunque, quizás, esta ubicación no sea extraña al postulado de la "moral interna" del derecho de L.L. Fuller, que se corresponde con una idea de justicia procedimental en el derecho asimilable a los requisitos del Estado de derecho, y que dicho autor califica (lo que colisionaría con la posición del positivismo corregido) como "derecho natural procedimental".

2.c) Las posiciones que consideran que esa conexión entre derecho y moral es "necesaria" y (tiene naturaleza) "sustancial". Este punto de vista es equiparable al que mantiene el "iusnaturalismo". Es una visión que reduce la filosofia del derecho a (una determinada y fija) teoria de la justicia. También aquí, pongamos por caso, podriamos situar las "excepciones" al positivismo que ampara Gustav Radbruch ante supuestos extremadamente injustos del derecho positivo según define la denominada "fórmula Radbruch", 94 o el punto de vista de R. Dworkin, o el postpositivismo de R. Alexy y su argumento sobre la injusticia del derecho partiendo de la anterior fórmula Radbruch.

92 Peces-Barba, G., Ética, poder y derecho, Madrid, Centro de Estudios Políticos y Constitucionales, 1995, pp. 63 y ss.

93 Peces-Barba, G., Lecciones de derechos fundamentales, con la colaboración de R. de Asís Roig y M.C. Barranco, Madrid, Dykinson, 2005, pp. 29-47.

94 Véase Radbruch, G., Filosofía del derecho, Granada, Comares, 2007. 